\title{
Using a discrete product model to determine the design element junctures
}

\author{
Mariya Lavrentyieva ${ }^{l}$, and Aleksey Govorkov ${ }^{1, *}$ \\ ${ }^{1}$ Irkutsk National Research Technical University, 664074, Irkutsk, Russian Federation
}

\begin{abstract}
This paper describes a discrete model of a standard airframe part. The model is intended for determining the junctures between the design elements of a node (unit) in the pre-assembly procedures. We herein propose an algorithm selecting base surfaces for basing the product being assembled; selections are made on the basis of the 3D model of such product.
\end{abstract}

\section{Introduction}

Making pre-production processes (PPP) more efficient has recently become one of the most relevant questions. The current trends of scientific and technical progress enable significant enhancements in many areas of mechanical engineering, including aircraft building; however, assembling still involves intensive manual labor, slowing down the development of this industry as a whole.

The current state of the art allows for using various software packages to make pre-production processes in engineering more efficient.

\section{Relevance and scientific importance}

In pre-production, the main objective is basing the part, i.e. ensuring it is positioned correctly. After a part is based, it must be locked. To ensure it does not move in the chosen coordinate system, you must impose six bilateral geometric relationships, for which they would need a set of reference anchor points. If one or more of them is missing, the part will have one or more degrees of freedom. This means that, in the direction of the missing anchor points, the position of the part will be determined by its juncture to another part.

\section{Problem Statement}

Two or more adjoining parts are referred to as joint parts. The surfaces in such a juncture are referred to as joint surfaces.

Each part is generated in its own coordinate system; when assembled in a single file, their coordinates are adjusted relative to the working coordinate system (WCS) of the assembler file, which means that before one can talk about the junctures, they have to know the minimum number of anchor points and the position of each part in the assembly, as these factors are crucial for basing.

\section{Theory}

Let us use a beam calculation model that holds for those structures wherein the size along one axis significantly exceeds their cross-section, whereby there is no abrupt change in the rigidity and the anchoring elements, as shown in figure 1.

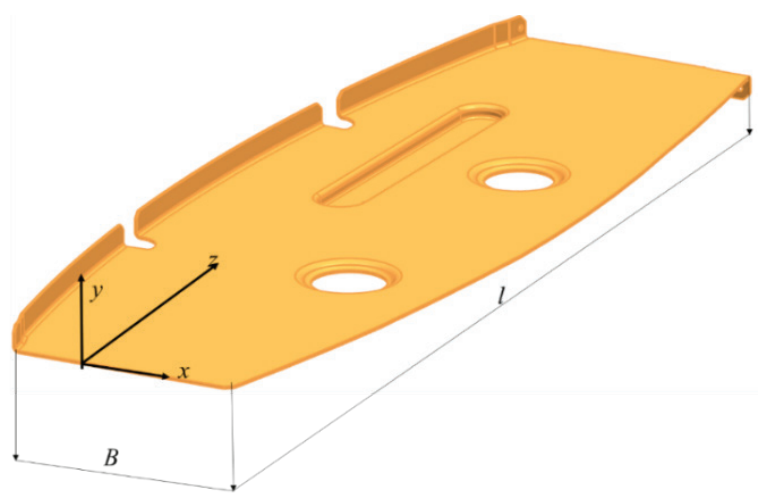

Fig. 1. Rib wall

To determine the deflection of the part, let us select a stripe along the generatrix, where there is a uniformly distributed load $\mathrm{q}$ along the length and a pressing force at the anchoring points, as shown in Figure 2.

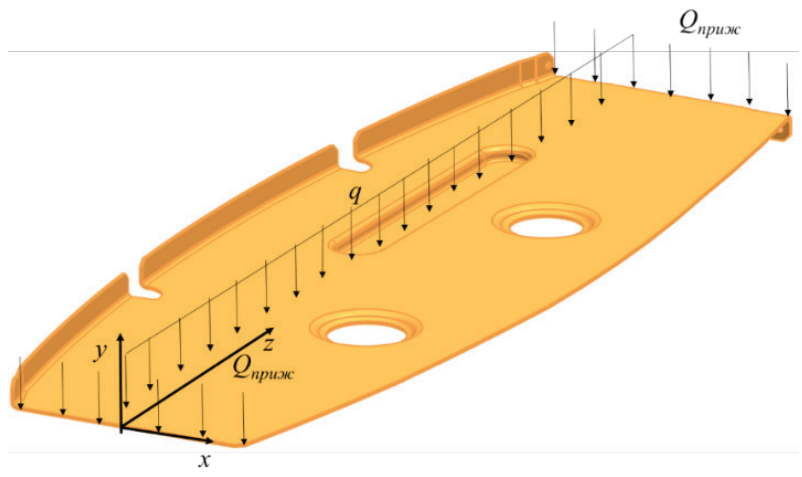

Fig. 2. Calculation chart for a rib wall

\footnotetext{
* Corresponding author: govorkov as@istu.edu
} 
Then, the maximum deflection in the middle is calculated using the formula (1), while the maximum distance between the anchor points is calculated using the formula (3).

$$
w_{\max }=\frac{q l^{4}}{8 E J_{x}}+\left(\delta_{б \phi y}-\delta_{\partial e m}\right)=\frac{\rho F g l^{4}}{8 E J_{x}}+\left(\delta_{\sigma \phi y}-\delta_{\partial e m}\right),
$$

where $\mathbf{E}$ is the first genus modulus of elasticity for the material of the part, MPa; $\mathbf{J x}$ is the moment of inertia of the section relative to the axis $\mathrm{x}-\mathrm{x}, \mathrm{m} 4 ; \mathbf{E} \mathbf{E} \mathbf{x}$ is the rigidity of the profile, $\mathrm{N} \cdot \mathrm{m}^{2} ; \boldsymbol{\rho}$ is the density of the material of the profile, $\mathrm{kg} / \mathrm{m}^{3} ; \mathbf{g}$ is the free-fall acceleration, $\mathrm{m} / \mathrm{s}^{2} ; \mathbf{F}$ is the area of the profile cross-section, $\mathrm{m}^{2}$; manufacturing error, $\mathrm{mm}$; $\boldsymbol{\delta} \boldsymbol{\sigma} \boldsymbol{\phi} \mathbf{y}$ is the manufacturing error of base anchoring devices of assembly fixtures, $\mathrm{mm}$.

Using the formulas (3.2)

$$
w_{\max } \leq w_{\partial o n},
$$

where $\mathbf{w}_{\max }$ is the maximum deflection, $\mathrm{mm}$; $\mathbf{w}_{\text {доп }}$ is permissible deflection, $\mathrm{mm}$.

and (3.3.), we obtain:

$$
l \leq \sqrt[4]{\frac{8\left(w_{\text {до }}-\delta_{\text {бфy }}+\delta_{\text {деm }}\right) E J_{x}}{\rho F g}} .
$$

Substituting all the values in the formula (3), we obtain the maximum distance between the anchor points lmax for all the parts made from beam-type profiles.

If the part anchoring is vertical, the deformation caused by the pressing force and the deformation caused by the own weight of the part are less than the maximum deflection wmax. For all of the cases where the preliminary value of the distance between the anchor points lmax, thereby ensuring the rigidity of the parts in assembly.

To simplify the search for the location by the parts coordinate measurement point, let us calculate the point of the center of mass of the part gц. The coordinates of the center of mass are always specified relative to the working coordinate system (WCS), which for the assembly units of aeronautical engineering parts shall coincide with the principal axes of the aircraft.

Using the movement matrix Mt relative to the working coordinate system of the assembler file.

$$
M_{t}=M_{r} \times M_{v},
$$

Where Mt is the movement matrix; $\mathbf{M r}$ is the rotation matrix; $\mathbf{M v}$ is the transition matrix.

$$
M_{\text {trans }}=\left|\begin{array}{lll}
x x_{0} & x y_{0} & x z_{0} \\
y x_{0} & y y_{0} & y z_{0} \\
z x_{0} & z y_{0} & z z_{0}
\end{array}\right| \times\left|\begin{array}{l}
x_{v} \\
y_{v} \\
z_{v}
\end{array}\right|=\left|\begin{array}{l}
x_{0}+x_{i} \\
y_{0}+y_{i} \\
z_{0}+x_{i}
\end{array}\right| .
$$

Accordingly, the coordinate placement of the other parts of the assembly unit shall be calculated by the center of mass relative to the working coordinate system of the assembly.

\section{Practical significance experimental results}

and

The position of each part is now known, and we can start determining the junctures of the parts of the assembly unit. In essence, the principle is still valid that was used to identify the inter-element linkages to determine the structure of the part.

For instance, for parts 1 and 2 that are sets M1 and M2 consisting of i surfaces pi, each surface contains at least three points, but in fact it has many more points; therefore, we get a set $\mathrm{Mi}=\{\mathrm{p} 1, \mathrm{p} 2, \ldots \mathrm{pj}\}$ consisting of subsets $\mathrm{Pi}=\{\mathrm{g} 1, \mathrm{~g} 2, \ldots \mathrm{gj}\}$, where $\mathrm{gj}$ is a point belonging to the surface.

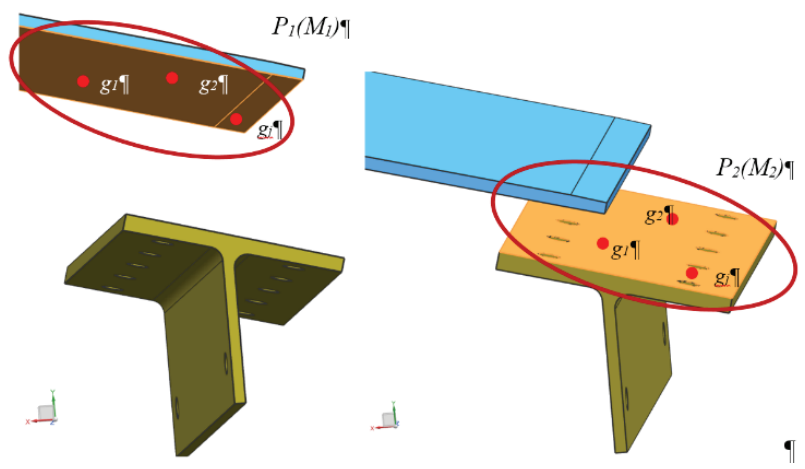

Fig. 3. Juncture surfaces of the parts in an assembly unit

In this case, the subset of points $\{\mathrm{g} 1, \mathrm{~g} 2, \ldots \mathrm{gj}\} \in \mathrm{p} 1$ (M1) and $\{\mathrm{g} 1, \mathrm{~g} 2, \ldots \mathrm{gj}\} \in \mathrm{p} 2(\mathrm{M} 2)$, i.e. the subset of points gj is coincident for surfaces of different parts p1 (M1) $\cap$ p2 (M2), which in its turn means these surfaces are juncture surfaces, and parts 1 and 2 are joint through these surfaces $\mathrm{p} 1 \subseteq \mathrm{M} 1$, a $\mathrm{p} 2 \subseteq \mathrm{M} 2 \Rightarrow \mathrm{M} 1 \cap \mathrm{M} 2$.

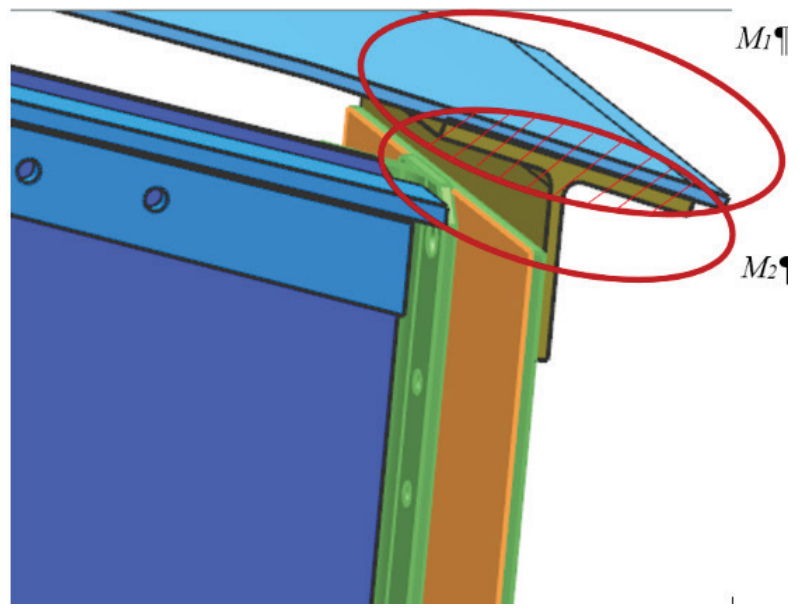

Fig. 4. Juncture of parts in an assembly unit

To determine that the subset $\{\mathrm{g} 1, \mathrm{~g} 2, \ldots \mathrm{gj}\}$ is the common subset for surfaces pi of different parts, we compare the coordinates $\mathrm{x}, \mathrm{y}, \mathrm{z}$ for all $\mathrm{gj}$, and if the coordinates coincide, the points coincide, too.

As a result, we come to know the position, the surfaces, and the junctures for every part in the assembly unit; taking into account the first analysis, we know all the lines, all the existing surfaces, and even the points. Each 
of those primitives is a base (assembly base, technology base, or design base); however, it does not make sense to use all of them; we have to single out the bases that are relevant to the problem to solve.

\section{Conclusion}

Using a discrete product model to determine the design element junctures allows for determining:

- the structure of the product;

- the design and technological parameters of the product;

- the set of the bases of the product.

It also makes it possible to obtain data for identifying the relevant bases to later solve the problems related to designing the technological tooling for product assembly.

\section{References}

1. Y.D. Amirov, Design for manufacturability, Biblioteka konstruktora (M.: Mashinostroenie, 1990)

2. A.A. Cherepashkov, N.V. Nosov, Computer technology, modeling and automated systems in mechanical engineering (Infolio. Volgograd, 2009)

3. A.A. Cheslavskaya, V.V. Mironenko, A.V. Kolesnikov, N.V. Maksimenko, V.V. Kotov, Choosing an efficient method for forming parts by means of an engineering analysis performed with the use of a CAE system, Metallurgist, №58. Issue 11-12, pp. 1051-1059 (2015)

4. P. Emad, N Abouel, A. K. Kamrani, A new methodology. for extracting manufacturing features from CAD system, Computers \& Industrial Engineering 51, pp. 389-415 (2006)

5. R. Duda, Image recognition and scene analysis, Richard O. Duda, Peter E. Hart (M.: Mir, 1976)

6. A. S. Govorkov, Technique of designing of the product of aviation technics with maintenance of the set criteria of adaptability to manufacture, Journal of International Scientific Publications: Materials, Methods \& Technologies, Vol. 5. Issue 3, pp. 156161 (2011)

7. A.S. Govorkov, A.S. Zhilyaev, The estimation technique of the airframe design for manufacturability, IOP Conference Series: Materials Science and Engineering, Vol. 124, Issue 1, pp. 01 (2014)

8. V.E. Gozbenko, S.K. Kargapolcev, V.V. Kondratiev, A.I. Karlina, N.V. Minaev, Vertical dynamics of the vehicle taking into account roughness gauge, Proceedings of the XV International Academic Congress "Fundamental and Applied Studies in the Modern World", V. XV. "Oxford University Press", pp. 373-383 (2016)

9. V.E. Gozbenko, S.K. Kargapoltsev, D.N. Kornilov, N.V. Minaev, A.I. Karlina, Simulation of the vibration of the carriage asymmetric parameters in MathCAD, International Journal of Applied Engineering Research (IJAER), V. 11, Number 23, pp. 11132-11136 (2016)
10. V.A. Grechishnikov, R.M. Khusainov, D.R. Akhkiyamov, S.Y. Yurasov, O.I. Yurasova, Identifying the primary rigidity axes in the elastic system of a metal-cutting machine, Russian Engineering Research, Vol. 36, No. 8, pp. 673-676 (2016)

11. R.M. Khusainov, I.F. Sharafutdinov, Methods of assessing the dynamic stability of the cutting process using Unigraphics NX. IOP Conf. Series: Materials Science and Engineering 134, 012042 (2016)

12. I.M. Kolganov, The ways of design for manufacturability increasing on airplane industry, CHast' 1: Uchebnoe posobie (Ul'yanovsk: UlGTU, 2003)

13. P.M. Krastyaninov, R.M. Khusainov, Selection of equipment for machining processing of parts using NX and TEAMCENTER programs, IOP Conf. Series: Materials Science and Engineering 134, 012041 (2016).

14. Y.I. Karlina, A.S. Govorkov, Design and Technology Parameters of the Nomenclature of Products Made When Automating Pre-Production Processes; Choosing the Basic CAD System of the Enterprise for Creating a Digital Product Mockup, Advanced Technologies. System Analysis. Modeling, Issue 3 (51), pp. 49-55, (2016).

15. A.S. Govorkov, A.S, ZHilyaev, Practical application of the "DFM analysis system" during the process control products aircraft equipment, Trudy MAI, Issue 74, pp. 21 (2014).

16. R. Akhatov, A. Govorkov, A. Zhilyaev, Software solution designing of "The analysis system of workability of industrial product" during the production startup of aeronautical products, International Journal of Applied Engineering Research, Vol. 10, Issue 21, pp. 42560-42562, (2015).

17. A.K. Shmakov, V.V. Mironenko, K.K. Kirishina, A.S. Stanislavchik, V.V. Kotov, Effect of the Average velocity of the free part of the semifinished product on the process of pneumothermal forming in the superplastic regime, Metallurgist, Vol. 57, Issue 1-2, pp. 8-12 (2013).

18. P. Subrahmanyam, M. Wozny, An overview of automatic feature recognition techniques for computer-aided process planning. Computers in industry, Vol. 26, pp. 1-21 (1995)

19. J. Tou, Pattern recognition princples (Moscow: Mir, 1978). 